\title{
Paying attention: Hippocratic and Asklepian approaches ${ }^{\dagger}$
}

\section{Robin Downie}

\begin{abstract}
SUMMARY
Psychiatry predominantly uses an evidence-based way of understanding patients. Over the past two decades, however, the idea has become acceptable that something can also be learned from the arts. This article suggests a precise role for 'narrative understanding', but argues that something further can be learned by examining a particular mode of attention - that which an experienced viewer might give to a painting or listener to a piece of serious music. The article articulates the contrast between the detached attention of the scientist and the engaged attention of the artist in terms of two traditions of medicine: Hippocratic and Asklepian. It argues that it is possible to combine these and that the ways in which an informed viewer looks at paintings or listener listens to music can be models for this sort of attention.
\end{abstract}

\section{DECLARATION OF INTEREST}

None.

Over the past two decades, doctors have realised that something of use to psychiatry can be learned from the arts and humanities. A common suggestion has been that the arts and humanities can offer a kind of understanding of human behaviour - often called 'narrative understanding' - that represents an alternative to the scientific or causal explanation of the kind commonly used in psychiatry (Evans 2001). The claim is that this kind of understanding - the kind that comes from following an unfolding story - might at least complement the scientific explanation of behaviour and sometimes indeed might bring about an improvement in a patient's condition (Saunders 2005).

There tends to be a certain vagueness in the literature about how this might work, but I shall later make more precise the role of narrative understanding in a consultation. In any case, an understanding of the role of narrative is only one way in which the arts and humanities can assist in the education of a psychiatrist. I wish to suggest a second way, one that includes the use of narrative but requires us to consider arts other than literature and drama. It will be helpful to begin by outlining briefly two traditions of medicine.

\section{Two traditions of medicine: Hippocrates and Asklepios (or Asclepius)}

These two traditions go back to the origins of Western medicine in the Greek world. The ideas that each tradition expresses are central to appreciating the eclectic nature of modern psychiatry. I must, of course, stress that the origins of medicine are obscure, but fortunately their scholarly complexities are irrelevant to my theme. In identifying the two traditions of medicine, I am concerned with two tendencies in medical practice rather than historical detail, even if that detail were available. These tendencies were present at the very beginning of Western medicine and I shall discuss them in terms of the two traditions.

\section{The Hippocratic tradition}

The first tradition is that of Hippocrates, which is currently dominant. Hippocrates was a Greek physician who was born around 460 BC. He and his school were dedicated to investigating the rational, scientific basis of medicine. This scientific approach ignores the individuality of patients and concentrates on what diseases have in common. It is assumed that diseases follow a pattern, the causal laws of which can be discovered. When they are discovered, treatments may be devised and applied regardless of the individual experience of illness and disease. The central doctrine of the Hippocratic school is that every disease, every human ailment, has a cause that can be discovered and is curable, and that this knowledge is generalisable. This belief is the foundation of Western scientific medicine and continues to inspire research and treatment as much in psychiatry as in other branches of medicine. A belief in the causal origins of all disease pervades the Hippocratic writings. For example, he writes: 'Every phenomenon will be found to have some cause' or 'each disease has a natural cause and nothing happens without a natural cause' (Lloyd 1983: p. 29).

\section{The Asklepian tradition}

The tradition of Asklepios is also Greek in origin and is older than the Hippocratic tradition. The two traditions flourished together and were not
Robin Downie is Emeritus Professor of Moral Philosophy at Glasgow University, UK. His interests include the philosophy of medicine, palliative care and using the humanities in medical education. His book (with Fiona Randall) The Philosophy of Palliative Care won the Medical Journalists Association prize in 2007 for the best book in a medical specialty, and his End of Life Choices (with Dr Randall) was highly commended in the 2010 BMA international book competition. Correspondence Professor Robin Downie, University of Glasgow, Glasgow G12 800, Scotland, UK. Email: R.Downie@philosophy.arts. gla.ac.uk

†For a commentary on this article see pp. 369-371, this issue. 
seen as mutually exclusive. Asklepios is a shadowy figure in Greek thought (Hart 2000). He was believed to be the son of Apollo (the god of healing and the arts) by a mortal woman. The Asklepian tradition stresses healing, but in the context of our acceptance of our mortality. The temples of Asklepios, which were the centres of healing, contained harmless serpents (coluber longissima). It was thought to be the mystical hypnotic gaze of the serpent that was healing and the fact that serpents change their skin was also symbolic. Moreover, the atmosphere of the temple and the quiet repose and dreams of the patients were important in the healing process, for the healing comes from within the patient (Mitchell-Boyask 2008). There is an important contrast here with the Hippocratic tradition of modern medicine where the emphasis is on external intervention.

The Asklepian tradition of the healing gaze of the serpent and the changes coming from within the patient (as in changing one's skin) translates well into psychiatry, or at least into some branches of it. In a sense, the gaze corresponds to the psychiatrist's attention to the patient, to the careful waiting and listening, and to acceptance of the particularity of the patient as a unique and important person in the context of our knowledge of our shared humanity. An approach of this kind is not manipulative and does not threaten the patient's integrity. It can be seen in religious terms - as suggested by the location of the treatment in temples - but a religious interpretation is not essential, as I shall suggest later. Rather, healing derives from the careful application of knowledge while constantly attending to the patient. The insights of this tradition require some further development. There are three points that are relevant to a psychiatric consultation, concerning the manner, the diagnostic insights and the ethics.

\section{The Asklepian manner}

The manner consists of quiet waiting and listening, concentrating attention on the patient. At this point, it will be said: "We know this, we do it already, and it is taught in courses on communication and listening skills'. There is indeed a vast literature on communication skills, but does this literature really express the manner of the consultation as hinted at in the Asklepian approach, or does it rather distort human communication? The very term 'communication skills' is the give-away in that it suggests that there are generalisable skills that are teachable and learnable and, therefore, widely applicable. Perhaps there are, but they are unlikely to extend much beyond such matters as avoiding technical terms, not speaking too quickly, repeating the message and so on. These things are, of course, of the first importance because a common criticism of doctors generally is that they are deficient in such matters. Nevertheless, attempts to have a complete reduction of communication to a set of discrete skills is bound to fail. Patients and their problems and psychiatrists and their personalities are all too varied for any reductionist approach to work. Indeed, interaction with patients may be adversely affected if trainee psychiatrists are encouraged to inhibit their own natural responses and substitute consciously adopted trained responses (Randall 2006). Human communication will become a manipulative technique.

The problem arises when there is an attempt to use the approach of Hippocrates in an area of human experience for which it is not suited. The Asklepian tradition has become distorted because it is being interpreted in terms of the protocols, training courses, questionnaires, scales and measurements that have become dominant in the Hippocratic tradition at the present time. A scientific study from 2011 argues:

'The concept of communication skills is inherently reductionist inasmuch as it proposes that complex behaviour such as conducting a consultation or building a relationship can be atomised into component skills' (Salmon 2011: p. 218).

The authors conclude that, granted the uncertain dynamics of consultation, good communication must be inherently creative.

\section{Asklepian diagnostic skills}

Turning now to diagnostic skills, we can agree that they are mainly the prerogative of what I am calling the 'Hippocratic approach' of modern medicine. Diagnostic skills involve knowledge of the whole battery of evidence-based tests, scans and techniques that are essential to contemporary psychiatric practice. Critics will argue that such tests omit the human element in the consultation and that the human element is especially important in psychiatry. How is that to be covered? A common reply is that what is not covered by contemporary Hippocratic techniques of diagnosis is covered by a term that has become the 'Japanese knotweed' of medical terminology - empathy. The idea is that while Hippocratic medicine may provide explanations of the patient's behaviour, it is empathy that provides understanding.

However, there are serious problems with the concept of empathy (Macnaughton 2009). I appreciate that there is a huge body of literature on empathy, but I shall confine myself to making four points: 
- it is unclear what it is;

- it looks inward rather than outward;

- what the concept is attempting to express can be better expressed by other concepts; and

- it runs together epistemological and ethical points.

The first problem with 'empathy' is knowing what it is. 'Empathy involves being able to appreciate another person's reality and to convey that understanding sensitively' (Parkes 1996). Thus, empathising has two components. The first is the ability to understand and share the emotions of another person so as to enter their experiential world and the second is to behave in such a way that the patient believes that the psychiatrist has achieved this level of understanding. But there is a fundamental ambiguity here. Are we understanding what the other person might be feeling or thinking, or what we might feel or think in the same situation? The official answer is, no doubt, that we are trying to understand what the other person is feeling or thinking. But how is it possible, even in principle, to know that what we are 'understanding' is the patient's feelings or thoughts, as distinct from imagining what our own might be in the situation? As Macnaughton puts it, 'It is potentially dangerous and certainly unrealistic to suggest that we can really feel what someone else is feeling [...] Any mirroring of feeling will always differ quantitatively and qualitatively from that patient's experience' (p. 1941).

Second, 'empathy' directs our attention towards our own feeling states when 'Asklepian' attention is directed outwards towards the patient. Oddly enough, Asklepian attention is well described by Parkes and colleagues (1996) in their section on active listening:

'This demands giving people our total attention. It is not a passive process but an active engagement. It requires the use of all our senses. It means listening with our ears to what is being said and to the tone of voice, listening with our minds to understand the message contained [...] Listening in this way enables clients to feel that we are really there with them and value who they are' (p. 60).

In other words, our own feelings, whether of empathy or anything else, are of minimal importance.

Third, something of importance is nevertheless being indicated by the use of the term 'empathy'. It is that certain 'something' that is missing from an attempt to understand a patient's behaviour entirely in terms of the assumptions of the Hippocratic model - from the outside, as it were. Anthropologists face a similar problem when attempting to understand a primitive society.
It is not adequate for them simply to describe the behaviour; they must see the meaning of this behaviour in a way of life (Winch 1967). Similarly, to understand a patient a psychiatrist must understand the meaning of the behaviour for the patient. This is the context in which the idea of narrative has an important role. An understanding of meaning requires close attention to the patient's unfolding story. It is in this way to return to the question raised at the start - that narrative understanding can complement scientific (Hippocratic) explanation. Indeed, sometimes it may even bring about an improvement if the psychiatrist can suggest that the patient's unfolding story is open to another, less destructive meaning. To achieve the understanding that supplements Hippocratic explanation, the psychiatrist must search for meaning in the patient's story rather than make a vain attempt to share feelings.

\section{Asklepian ethics}

The fourth point is that 'empathy' confuses an epistemological point with an ethical point. To make patients feel that the psychiatrist is there with them, as Parkes et al stress, may not help the psychiatrist to understand the patients' problems but it is important ethically in the Asklepian approach. It will be said that most medical training courses now contain instruction on ethics and indeed postgraduate written or oral examinations may contain questions on ethics. This is certainly true and to be welcomed. However, their unavoidable weakness is that they necessarily comprise generalised material to be taught and learned as of universal application. In other words, ethics courses are 'Hippocratic' in their nature. Like the Oath from which medical ethics has developed, what is taught purports to instruct what the psychiatrist must always do, such as 'respect the patient's autonomy'. But this approach, whatever its merits, does not get to the heart of ethical excellence in psychiatric behaviour, which is well expressed by Parkes (1996) as enabling the patient to feel that the psychiatrist is really there with them and values who they are.

\section{Combining the traditions}

Granted that I have provided an outline of what I am calling the 'Asklepian' approach, and granted that I am in no way belittling the Hippocratic or evidence-based approach, the question arises as to whether and, if so, how the two traditions might be combined. Can we unify the insights of both traditions? 


\section{The 'I-Thou' relationship}

A striking example from 1923 by Martin Buber (1937) suggests how the two traditions might be combined. The 20th-century philosopher/ theologian introduced a new phrase. In his most famous book he speaks of the 'I-Thou' relationship. Buber contrasts this with what he calls the 'I-It' relationship. In the I-It relationship we see an object, or perhaps another person, in terms of causality or function. Most obviously, we are in an I-It relationship with a thing of which we make use, a hairbrush, say. We can also be in an I-It relationship with another human being. This is not necessarily a bad thing; we all must make use of each other if social life is to continue. But we are in an I-Thou relationship with a friend, if we appreciate each other for what we are and questions of instrumentality are not in the forefront of our minds. The question that Buber raises is whether it is possible to combine the two attitudes. This is precisely the question of whether we can combine the Asklepian mode of attention with that of the scientific mode of Hippocrates. Buber discusses the question in terms of a striking image:

'I consider a tree. I can look on it as a picture; still column in a shock of light, or splash of green shot with the delicate blue and silver of the background. I can perceive it as movement; flowing vein or clinging pith, suck of the roots, breathing of the leaves, ceaseless commerce with earth and air and the obscure growth itself. I can classify it in a species and study it as a type in its structure and mode of life. I can subdue its actual presence and form so sternly that I recognize it only as an expression of law, of the laws in accordance with which the component substances mingle and separate. I can dissipate it and perpetuate it in number, in pure numerical relation. In all this the tree remains my object, occupies space and time, and has its nature and constitution. It can, however, also come about, if I have both will and grace, that in considering the tree I become bound up in relation to it. The tree is now no longer It. I have been seized by the power of exclusiveness. To effect this it is not necessary for me to give up any of the ways in which I consider the tree. There is nothing from which I would have to turn my eyes away in order to see, and no knowledge that I would have to forget. Rather is everything, picture and movement, species and types, law and number, indivisibly united in this event. If I face a human being as my Thou, and say the primary word I-Thou to him, he is not a thing among things, and does not consist of things [...] nor is he a nature able to be experienced and described, a loose bundle of named qualities. But with no neighbour and whole in himself, he is Thou and fills the heavens' (Buber 1923: pp. 7-8).

The illustration is both obscure and inspiring. The details of its meaning can be passed over, since for our current purposes it is making four main points. First, it is stressing the importance of accurate observation, and observation with a variety of dimensions concerned with type, number, law, composition, forces in opposition, and so on. If we apply the analogy to the context of healthcare we can interpret it as saying that there is no substitute for a careful and accurate diagnosis of the patient's symptoms and underlying disease, and this (Hippocratic) concern must take priority. Second, this (Hippocratic) kind of observation can change into a particular kind of attention directed specifically at this object or person: 'I become bound up in relation to it [...] I have been seized by the power of exclusiveness'. This is the Asklepian moment. Third, the observation and the particular kind of attention are compatible: 'to effect [this attention] it is not necessary for me to give up any of the ways in which I consider the tree'. Fourth, this kind of attention is at the same time a recognition of the value of this unique individual: 'If I face a human being as my Thou [...] he is not a thing among things'. This is the ethical moment. In short, Buber is saying via this example that the I-It and I-Thou relationships can be unified. The Hippocratic, scientific observation of symptoms is compatible with Asklepian attention to the unique value of the patient who we are attending.

\section{Coexisting kinds of attention}

It is important to stress that Buber is not saying that the I-Thou relationship should always replace the I-It relationship. There is a temptation to interpret Buber in this way, especially at a time when phrases such as 'patient-centred care' are common (Kitwood 1997; Jewell 2011). Buber is claiming that the kinds of attention indicated by the terms 'I-Thou' and 'I-It' are not exclusive. This is surely of the first importance in a psychiatric consultation. 'Patients are persons'; 'Yes, but they are still patients and must be subject to Hippocratic as well as Asklepian attention'. Moreover, as I indicated earlier, 'I-Thou' or Asklepian attention may (but need not) be given a spiritual interpretation. As Buber goes on to say after the passage quoted: 'I encounter no soul or dryad of the tree, but the tree itself' (p. 8).

\section{Coexisting approaches to medicine}

There is one further question that must be answered. I am maintaining that the Hippocratic or scientific attitude is compatible with the special attention of the Asklepian attitude. But how can both exist simultaneously? How can a patient at one and the same time be observed with detached scientific attention and the engaged attention of the Asklepian attitude? The answer is that there 
seems to be a problem here only if we think of the situation in terms of a misleading image. If we interpret the attentive gaze of the psychiatrist as being like that of a searchlight that is either on or off then we might think that there is a problem. But a better image (to continue with lighting) is of the varied and coloured lighting of a nightclub. Human beings can switch between a range of technical attitudes and a number of human attitudes. It is this facility that makes it possible for the professional-patient relationship to be both technical and human, or Hippocratic and Asklepian. This is difficult to achieve - it requires experience and maturity. But exposure to two arts other than literature may assist with the identification of the relevant kind of engaged attention, and provide some practice in developing it.

\section{Painting and music}

\section{Painting}

One way of identifying this kind of attention is to take the example of the attention we give to a painting, or even the attention that an artist might give to a person or landscape, or to a tree that the artist was about to paint (as in the Buber example). As some readers will be aware, JAMA publishes prints of paintings on its front cover. Therese Southgate, who was Deputy Editor of $J A M A$, writes about the relevance of painting to the practice of medicine. In the preface to The Art of JAMA, she writes of her belief that deep affinities exist between medicine and the visual arts (Southgate 1997). She goes on to suggest what some of these are:

'Firstly, they do share a common goal: the goal of completing what nature has not. Each is an attempt to reach the ideal, to complete what is incomplete, to restore what is lost. Secondly, the practitioners of each have something in common. The first is observation, keen observation. Even more important than the first because it determines the quality of the first, is the necessity of attention [...] Attention does not seek anything, nor does it impose itself on what is before it. It simply waits in a state of readiness to receive; what it receives is the truth of the object before it. In the end, both art and medicine are about seeing: one looks first with the eyes of the body, next considers with the eye of the mind, and finally, if one has been attentive enough, one begins to see with the eye of the soul. If we remain in this vision, are patient enough and still enough, we begin to hear as well, somewhere deep in the depths beyond where words are formed [... It is in this same wordless language of the human spirit that the physician sees not just a disease nor even a patient but the person. It is in that moment that healing begins. Paradoxically, the healer is healed as well. That perhaps is the art of medicine' (Southgate 1997: p. xii).
The passage eloquently highlights that it is not the feelings of the professional that are important but the concentrated involved attention. Just as the artist tries to see things as they are and ignores her feelings (if any), so the psychiatrist should concentrate on the patient for what the patient is a unique individual.

Jonathan Green has persuasively made a similar point in this journal (Green 2009). He argues that works of art 'carry their cultural power by being ways of embodying states of mind' and that 'inferring mental states is not only a core psychiatric skill but also one we exercise in looking at art'. In a telling image he says: 'The painting sucks in attention to itself', or as the French philosopher Merleau-Ponty (1962) puts it: '[art is] the act of bringing truth into being'. My gloss on this is that, as far as psychiatry is concerned, the attentive act must be both Hippocratic and Asklepian.

\section{Music}

Perhaps an analogy from a different kind of art might reinforce the point I wish to make. A musician giving a performance must concentrate on, give full and engaged attention to, the music. A successful performance may evoke emotions in an audience, but the performer must remain in control of whatever feelings he or she may have, otherwise he or she might lose the place in the music. The attention, the listening with both the physical ear and the inner ear, takes precedence over any emotion. In a similar way, the attending psychiatrist directs his/her gaze towards the patient and is totally receptive to what the patient is communicating. This way of learning what the patient needs is both more effective and more humane than imposing structured interviews from the outside. It is in terms of this analogy from the arts of painting and music that I am interpreting the Asklepian notion of the healer's hypnotic gaze.

It is also worth noting (returning to Buber) that the humane attention in terms of which I am characterising the Asklepian approach is quite compatible with the detached observation of the Hippocratic approach. As Buber put it in the passage cited: 'There is nothing from which I would have to turn my eyes away in order to see, and no knowledge that I would have to forget. Rather is everything, picture and movement, species and types, law and number, indivisibly united in this event' (Buber 1923: p. 7). In a similar way, our understanding and appreciation of a painting as a piece of art is increased by a knowledge of the technicalities behind its creation - the mixing of the colours, the use of perspective and so on.
MCQ answers

$1 \mathrm{~d} \quad 2 \mathrm{a} \quad 3 \mathrm{~d} \quad 4 \mathrm{~d} \quad 5 \mathrm{e}$ 
Similarly, our appreciation of music is enhanced by some knowledge of its construction, its form, its contrapuntal textures and so on. It is only when attention to technicalities becomes dominant that the artistic experience is extinguished. Balance and proportion is everything. In a similar way, the attention of the psychiatrist must be balanced.

\section{Conclusions}

The scientific (Hippocratic) model of explanation is dominant in psychiatry. The humane or Asklepian aspects of psychiatry - the attempts to understand - are often thought to be covered by 'communication skills' and 'empathy'. But communication, if it is not to become a crude manipulative technique, must be creative and individualised. Furthermore, what is valid in the idea of empathy is better seen as attention to meaning in the patient's narrative. Of central importance to the whole process of psychiatric consultation is a certain kind of engaged attention characteristic of the Asklepian approach. It is illustrated in the engaged attention that can be given to a painting or to a musician in performance. This kind of attention is compatible with a scientific approach to the patient.

\section{References}

Buber M (1937) I and Thou (trans RG Smith). Continuum. Evans M, Finlay I (2001) Medical Humanities. BMJ Books.

Green J (2009) Form and mental state: an interpersonal approach to painting. Advances in Psychiatric Treatment 15: 137-45.

Hart G (2000) Asclepius: The God of Medicine. Royal Society of Medicine.

Jewell A (2011) Spirituality and Personhood in Dementia. Jessica Kingsley Publishers.

Kitwood T (1997) Dementia Reconsidered: The Person Comes First. Open University Press.

Lloyd D (1983) Hippocratic Writings. Penguin Books.

Macnaughton J (2009) The dangerous practice of empathy. Lancet 373 : 1940-1.

Merleau-Ponty M (1962) The Phenomenology of Perception (trans C Smith). Routledge and Kegan Paul.

Mitchell-Boyask R (2008) Plague and the Athenian Imagination: Drama, History and the Cult of Asclepius. Cambridge University Press.

Parkes C, Relf M, Couldrick A (1996) Counselling in Terminal Care and Bereavement. BPS Books.

Randall F, Downie R (2006) The Philosophy of Palliative Care: Critique and Re-Construction. Oxford University Press.

Salmon P, Young B (2011) Creativity in clinical communication: from communication skills to skilled communication. Medical Education 45: 217-26

Saunders C, Macnaughton J (2005) Madness and Creativity in Literature and Culture. Palgrave Macmillan.

Southgate M (1997) The Art of JAMA. Mosby.

Winch P (1967) The Idea of a Social Science. Routledge.
MCOs

Select the single best option for each question stem

1 Narrative understanding:

$a$ is based on a scientific model

$\mathrm{b}$ is causal in nature

c has replaced the scientific model of understanding

$\mathrm{d}$ is compatible with the scientific model of understanding

$\mathrm{e}$ is the only contribution that the arts can make to psychiatry.

2 Within the two traditions in medicine:

a Hippocrates claimed that medicine had a scientific basis

b the Hippocratic tradition influenced medicine only by the Oath c Asklepios stressed finding causes for disease

d Asklepios stressed external intervention

e the approaches of Hippocrates and Asklepios are incompatible.

3 Regarding communication:

a it can be atomised into component skills

b it requires trained responses

c empathy enables us to know what another person is feeling

d ethical rules can be taught

e ethics is reducible to rules.

4 Regarding paying attention:

a Hippocratic attention stresses the uniqueness of individuals

b Asklepian attention seeks generalisable types of symptom c Asklepian attention and Hippocratic observation are incompatible

d Asklepian attention involves a recognition of the value of a person

e modes of attention cannot easily be switched.

5 Regarding the arts:

a painting offers no helpful analogies with psychiatry

b appreciation is ruined by technical knowledge

c they are essentially inward-looking activities

$\mathrm{d}$ they are concerned only with feeling

e as in psychiatry, attention is a state of readiness to receive. 